\title{
OPEN A possible precursor prior to the Lushan earthquake from GPS observations in the southern Longmenshan
}

\author{
Qixin Wang ${ }^{1}$, Xiwei Xu ${ }^{1 \bowtie}$, Zaisen Jiang ${ }^{2}$ \& John Suppe ${ }^{3}$
}

Global Positioning System (GPS) stations installed in and around the epicenter of the Lushan earthquake (Mw 6.7), which occurred almost 5 years after the 2008 Wenchuan earthquake, recorded preseismic deformation corresponding to the Lushan earthquake within the southern Longmenshan thrust belt. A half-space dislocation model is used to simulate the theoretical values of the postseismic displacements caused by the $\mathbf{2 0 0 8}$ Wenchuan earthquake, and after transforming the reference frame and filtering the GPS displacement time series, the theoretical and observed GPS values are compared to identify the geodetic anomaly preceding the Lushan earthquake. The abnormal extent of this geodetic anomaly decreases with increasing epicentral distance for each GPS site. This geodetic signal reflects preslip along a locked section of the 2013 seismogenic fault, which caused the accumulation of elastic strain energy until the faulting strength was overcome, thereby generating the Lushan earthquake. Hence, this anomaly might be used as an observable and identifiable precursor to forecast an impending earthquake within a period of less than two and half years before its occurrence.

Predicting the magnitude and location of an earthquake prior to an impending seismic event has been a controversial subject of research over the past two decades ${ }^{1-3}$. At present, earthquake forecasting is a very difficult issue because very little about the earthquake mechanism is understood; moreover, the instruments needed to observe an earthquake are often not situated sufficiently close to the epicenter at the correct time ${ }^{4-6}$. Since the Global Positioning System (GPS) technology, some researchers have tried to detect possible precursors before an earthquake by analyzing preseismic strain rate $^{7}$, baseline distance ${ }^{8}$ or ionospheric maps ${ }^{9}$. However, researchers have difficulty explaining the relationship between the observed precursors and the epicenters. Furthermore, the location of the epicenter cannot be forecasted before an earthquake. Consequently, whether an observable and identifiable precursor anomaly precedes an impending earthquake has yet to be resolved ${ }^{10,11}$.

The Longmenshan thrust belt (LTB) is a $\mathrm{N}^{\circ} 2^{\circ} \pm 5^{\circ} \mathrm{E}$-trending crustal shortening boundary between the Bayan Har Block and the South China Block along the eastern margin of the Qinghai-Tibet Plateau ${ }^{12,13}$. The LTB has attracted considerable attention in the last 10 years, particularly as a result of the $2008 \mathrm{Mw} 7.9$ Wenchuan and $2013 \mathrm{Mw}$ 6.7 Lushan earthquakes that occurred along the thrust boundary ${ }^{14-19}$. The Wenchuan earthquake produced a complicated $240-\mathrm{km}$-long surface rupture zone in the middle segment of the LTB, while the Lushan earthquake occurred along the southern segment as a blind reverse-faulting event ${ }^{14-17,20-22}$. The distance between the rupture zones of these two earthquakes is $90 \mathrm{~km}^{23,24}$, and few earthquakes have occurred within this gap. During the Wenchuan earthquake, a significant stress increase resulted from coseismic oblique slip, which had the potential to trigger or hasten the occurrence of a destructive earthquake on the southern segment of the LTB ${ }^{18,19}$. Therefore, a well-designed temporary continuous GPS network comprising 10 stations (Fig. 1) was installed in and around the southern segment of the LTB soon after the Wenchuan earthquake by the Institute of Earthquake Forecasting, China Earthquake Administration (Fig. 1; Supplementary Table S1). All of these GPS stations recorded the preseismic deformation corresponding to the Lushan earthquake. Accordingly, any identifiable precursory signals recorded in the vicinity of the epicenter may be detected, thereby revealing heretofore unreported aspects of the earthquake process, and this knowledge may be used to forecast destructive earthquakes in and around the eastern Tibetan Plateau.

\footnotetext{
${ }^{1}$ National Institute of Natural Hazards, MEMC, Beijing 100085, China. ${ }^{2}$ Institute of Earthquake Forecasting, China Earthquake Administration, Beijing 100036, China. ${ }^{3}$ Department of Earth and Atmospheric Sciences, University of Houston, Houston, TX, USA. ${ }^{\varpi}$ email: xiweixu@vip.sina.com
} 


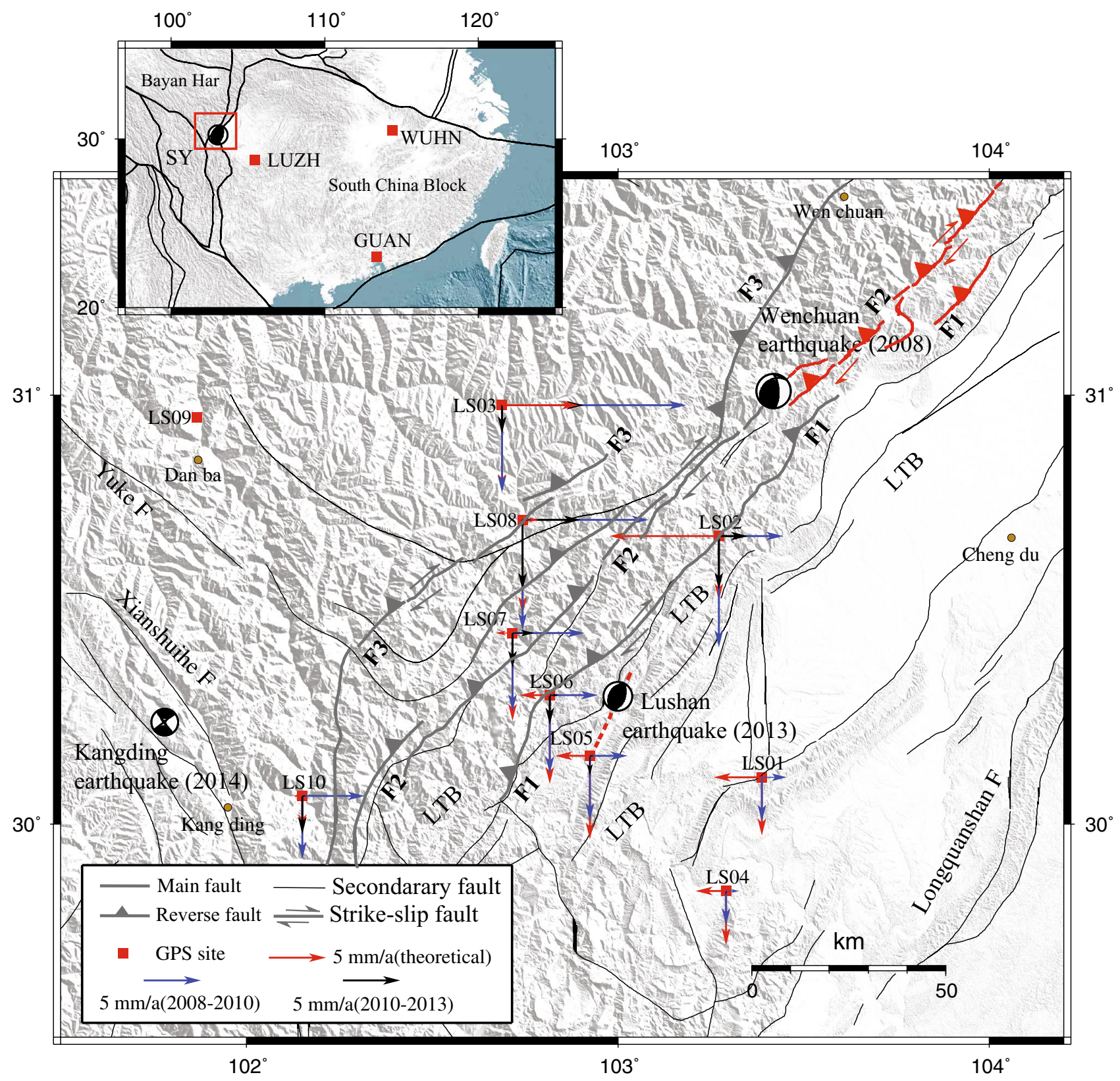

Figure 1. Sketch map showing the distribution of the installed continuous GPS stations (LS01-LS10) and the epicenters of the Lushan and Wenchuan earthquakes. WUHN, GUAN and LUZH in the inset map in the upperleft corner are the GPS reference stations in the South China Block, a stable tectonic domain. The red arrows are the postseismic theoretical velocities associated with the Wenchuan earthquake obtained by a half-space dislocation model. Blue arrows and black arrows are the observations at each GPS site. The LTB represents the Longmenshan thrust belt, which consists of the Pengguan fault (F1), Beichuan fault (F2) and Maowen fault (F3). The SY represents the Sichuan-Yunnan Block. Lines with solid triangles and arrows represent reverse faults and strike-slip faults, respectively. The red solid lines represent the surface rupture zone of the Wenchuan earthquake, while the red dashed lines represent the surface projection of the inferred seismogenic fault of the Lushan earthquake. Map is generated by GMT software, v. 4.5 .15 (http://www.soest.hawaii.edu/gmt/).

\section{Results}

Observations and simulations. The results reveal that the theoretical postseismic displacements at stations LS01, LS02, LS04, LS05, LS06, LS07 and LS10 have a westward component (Fig. 1). As previous work has shown ${ }^{14}$, the Wenchuan earthquake was a thrust fault earthquake. Thus, the westward component is reasonable because most of these stations, except LS07, are located on the footwall of the Beichuan fault (F2) (Fig. 1). LS07 is located far from the source fault of the earthquake, but the normal distance between the station and the fault is small. Therefore, it is difficult to judge the direction of the postseismic displacement based on its location ${ }^{25}$. We can only estimate the direction with theoretical value. However, in the reference framework of the South China 
LS05

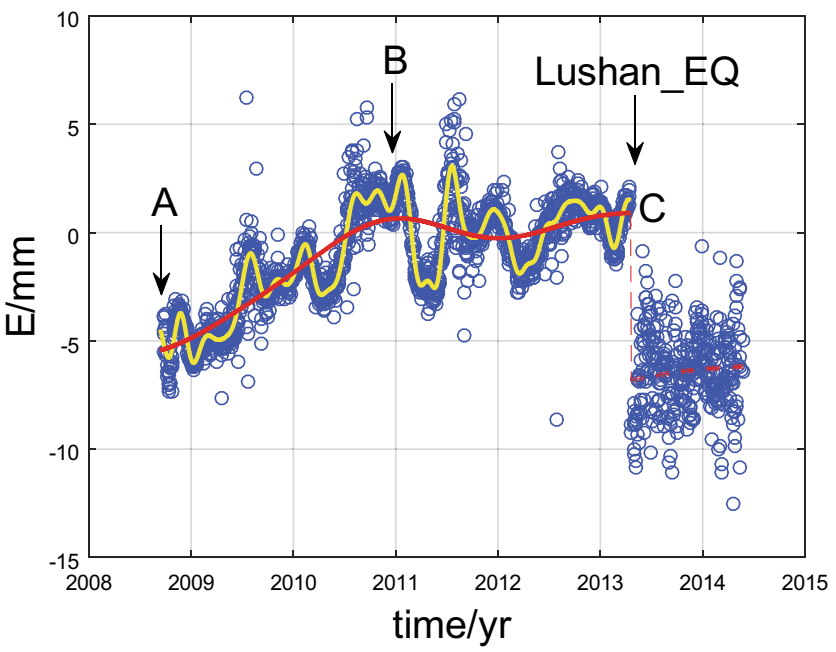

LS06

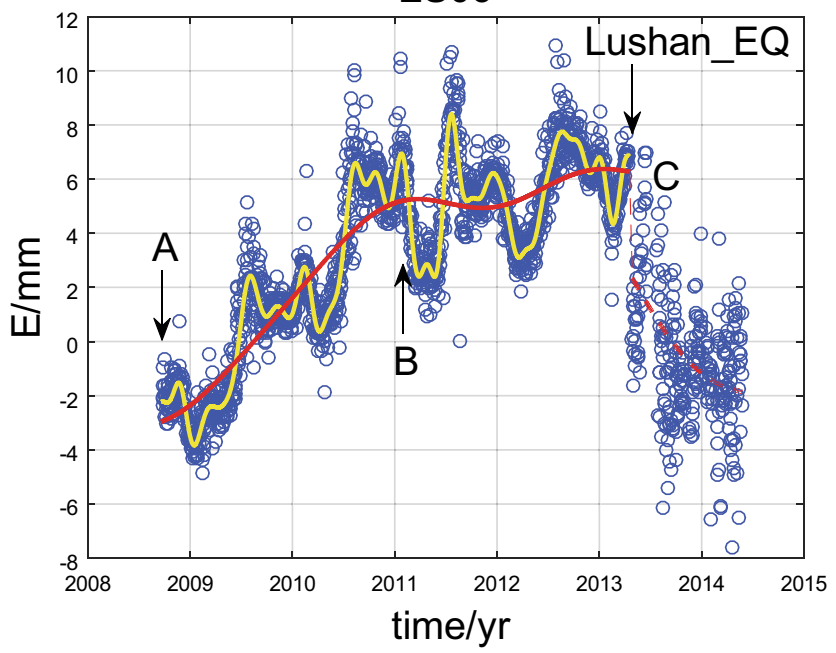

$\circ$ original data

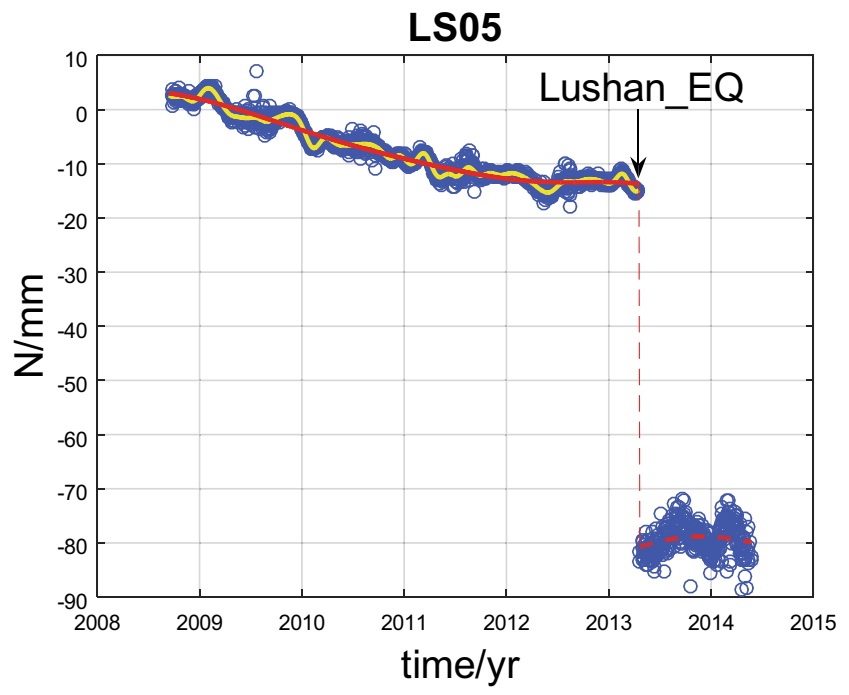

LS06

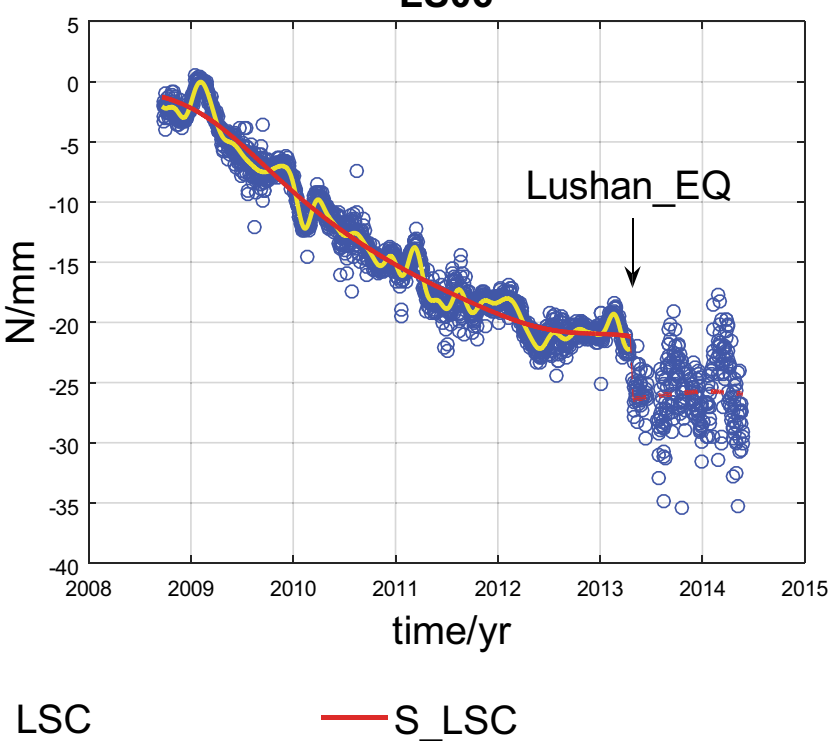

Figure 2. (a) Eastward and (b) northward displacement time series of stations LS05 and LS06. Blue circles are the original data; the yellow line represents the data filtered by the least-squares collocation method; and the red line signifies the secondary data without periodicity filtered by the least-squares collocation method. Section $A B$ presents a linearly increasing trend and a locked seismogenic fault. Beyond point B, section BC shows a stable stage and preslip motion along the seismogenic fault before the Lushan earthquake. Map is generated by Matlab software, v. R2018a (https://www.mathworks.com/).

Block, all of the GPS stations have an eastward component because the observations also include the eastward secular motion, which is larger than the westward postseismic slip due to the Wenchuan earthquake and thus controls the observed displacements at all the GPS stations. Motions of both the observed and the theoretical values have the same southward direction (Fig. 1).

Characteristics of observed time series. The site closest to the epicenter of the Lushan earthquake is station LS05 on the Bayan Har Block (approximately $17 \mathrm{~km}$ ), followed by station LS06 (Supplementary Table S1). As shown above, the eastward components at both stations contain both the secular motion and the theoretical postslip component associated with the Wenchuan earthquake. Theoretically, the eastward secular motion of the Bayan Har Block remains constant as a long-term loading strain, while the westward theoretical postslip component gradually decays to zero as a short-term loading strain, suggesting that the eastward displacements of these two stations should theoretically increase with time. We do observe a linear stress-induced increase in the eastward displacements of both LS05 and LS06 with velocities of $3.3 \sim 4.2 \mathrm{~mm} / \mathrm{yr}$ in the first 2 years after installation in addition to a similar pattern in the displacement time series (Figs. 2 and 3). However, the velocities at these stations obviously decrease after 2011 to very low values of $0.3 \sim 0.8 \mathrm{~mm} / \mathrm{yr}$ (Figs. 2 and 3). As a result, LS05 remained stable, exhibiting almost no eastward motion there after 2011(Fig. 2). This finding demonstrates 


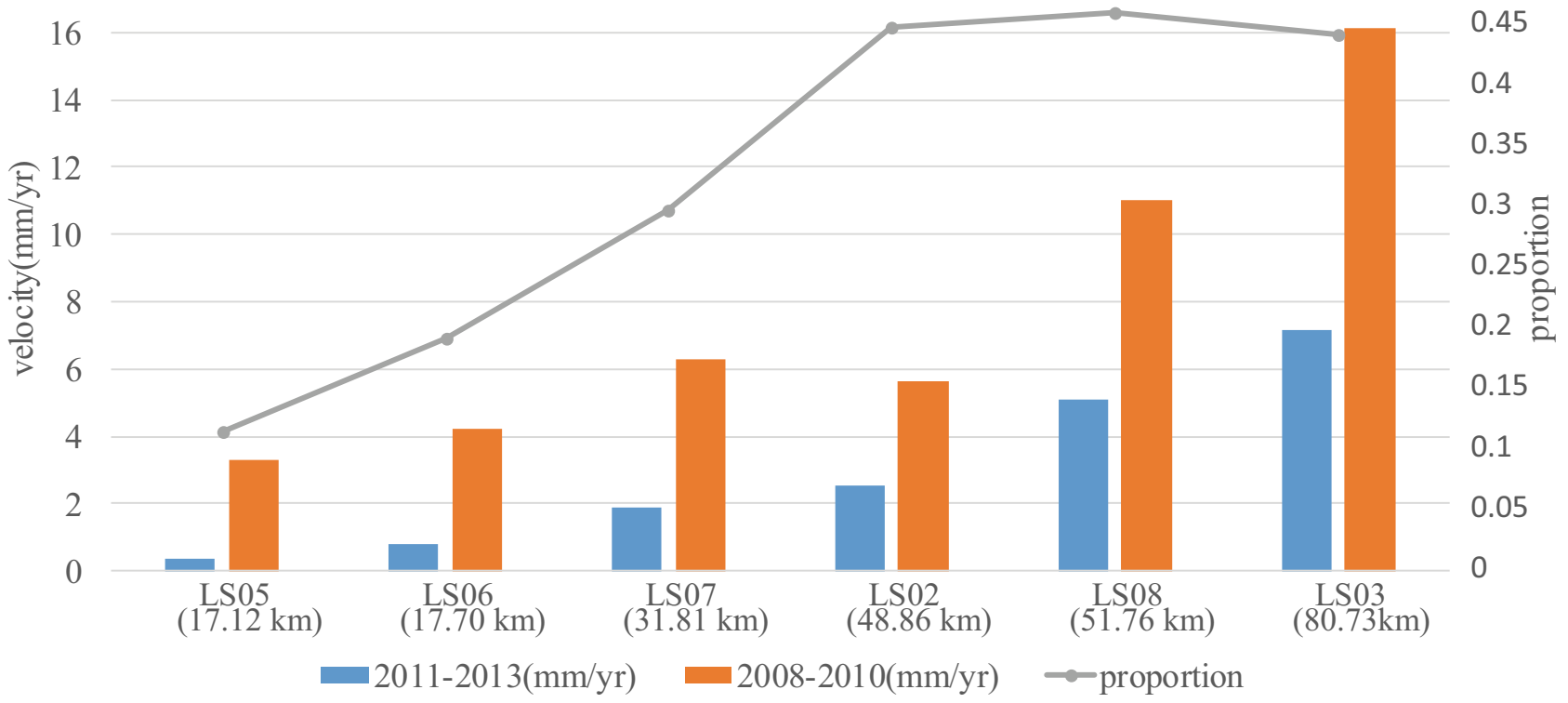

Figure 3. Eastward velocities during 2011-2013 and 2008-2010 and a comparison between the two periods. The abscissa is the name of the station and its epicentral distance. The bar chart displays the velocity of each station in the Bayan Har Block except LS10. The gray line is the difference between the velocity during 20112013 and that during 2008-2010. Map is generated by Matlab software, v. R2018a (https://www.mathworks. $\mathrm{com} /$ ).

that the beginning of 2011 marks a temporal inflection point, after which little or no near-field eastward displacement occurred at or around the epicenter, as depicted in section BC of the eastward displacement time series of stations LS05 and LS06 (Fig. 2).

Similarly, the eastward components of stations LS02 and LS07, approximately $49 \mathrm{~km}$ and $32 \mathrm{~km}$ from the epicenter, respectively (Supplementary Table S1), also resulted mainly from secular motion after subtracting the postslip deformation due to the Wenchuan earthquake. We also observe a preseismic anomaly similar to that reflected by the eastward displacement time series in the GPS data from LS05 and LS06 (Fig. 2), but this anomaly is not as obvious as that at LS05 and LS06. The velocity variations at LS02 and LS07 also display a temporal inflection point at the beginning of 2011, after which the eastward velocities diminish (Supplementary Fig. S1), slowing obviously from 5.6-6.3 mm/yr generally before 2011 to $1.9-2.5 \mathrm{~mm} / \mathrm{yr}$ after 2011 until the occurrence of the Lushan earthquake (Supplementary Fig. S1).

The data from stations LS03 and LS08, whose epicentral distances are greater than $50 \mathrm{~km}$ (Fig. 1 and Supplementary Table S1), are quite different from those at stations LS05 and LS06. The secular motion and postslip deformation caused by the Wenchuan earthquake at LS03 and LS08 have the same eastward components. Moreover, both their northward and eastward components readily conform to the postseismic exponential model $^{21}$ without obvious anomalies, and the velocities of the eastward displacements gradually decrease during the observation period, but no temporal inflection points are observed in the eastward displacement time series of LS03 and LS08 (Supplementary Fig. S2).

Station LS10 is the GPS site farthest from the epicenter of the Lushan earthquake (Supplementary Table S1), and the velocity at this site decays after February 2011 (Supplementary Fig. S1). However, the anomaly at LS10 may not be related to the Lushan earthquake owing to its location on the eastern side of the Xianshuihe fault, a major left-lateral strike-slip fault ${ }^{26}$. In contrast, this anomaly may be related to the $2014 \mathrm{Mw} 5.9$ Kangding earthquake $^{27}$ (Fig. 1). Furthermore, stations LS01 and LS04 are located on the footwall of the LTB on the South China Block, which is more rigid than the Bayan Har Block ${ }^{28}$. After transforming the reference framework to the South China Block, the motions at LS01 and LS04 are steady, and their eastward and northward motions both remain stable before the Lushan earthquake (Supplementary Fig. S3).

The relationship between the anomaly and the epicentral distance. The above analysis reveals an obvious decrease in the eastward velocity surrounding the epicenter of the Lushan earthquake approximately two and half years before its occurrence. In addition, the eastward velocity at each station is increasingly reduced with increasing proximity to the epicenter. To determine the relationship between the anomaly and the epicentral distance, the velocities recorded during 2011-2013 are compared with those recorded during 2008-2010 in the Bayan Har Block. The results demonstrate that stations within $50 \mathrm{~km}$ of the epicenter present obviously reduced eastward velocities before the Lushan earthquake and that the reduction in the eastward velocity is inversely proportional to the epicentral distance (Fig. 3). The velocity gradually increases outward for the stations within a range of $\sim 50 \mathrm{~km}$, whereas the velocities for the remaining stations outside the $\sim 50 \mathrm{~km}$ radius exhibit a similar pattern. Thus, the dramatic decrease in the eastward velocity (even to zero) at the epicenter observed at these 

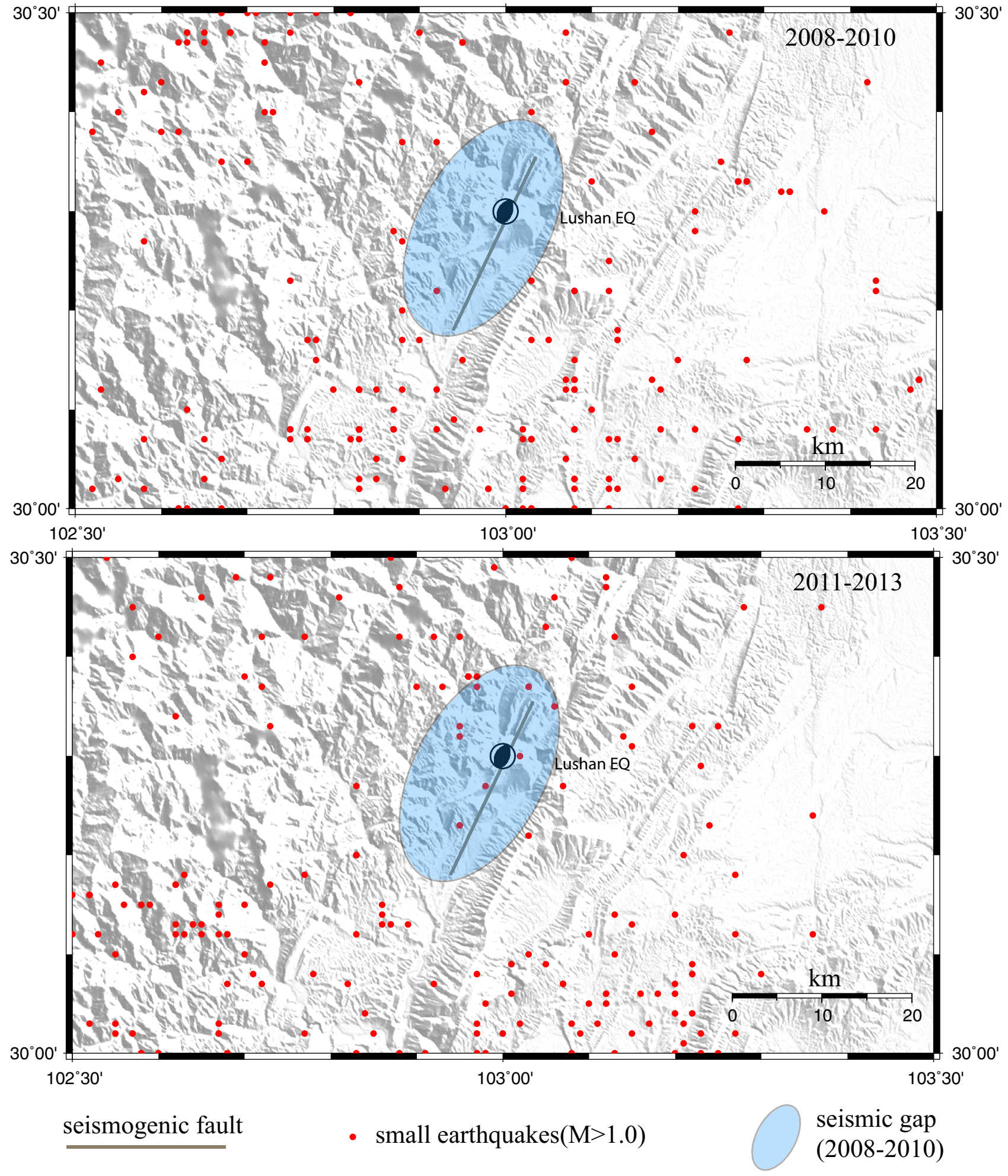

Figure 4. Small earthquakes in the vicinity of the southern segment of the LTB in the 2008-2010 and 2011-2013 periods. Red circles are small earthquake locations; the gray solid line is the seismogenic fault of the Lushan earthquake as mentioned in Fig. 1. Map is generated by GMT software, v. 4.5.15 (http://www.soest. hawaii.edu/gmt/). 
continuous GPS stations occurred only within a radius of $\sim 50 \mathrm{~km}$ centered at the expected epicenter. This nearfield phenomenon may be used as a precursor to locate impending earthquakes.

\section{Discussion}

Ultimate strength of the fault. The LTB has suffered from oblique crustal shortening throughout the Quaternary owing to the east-southeastward motion of the Bayan Har Block and its collision with the South China Block, which has accommodated India's northward penetration into Eurasia ${ }^{12,13}$. When this oblique shortening strain accumulates sufficiently to reach the ultimate strength of a locked fault segment within the LTB, that fault segment fails and leads to unstable faulting, that is, an earthquake. The slopes of the eastward displacement time series at stations LS05 and LS06 change significantly at the inflection point (B) (Fig. 2). Before point $\mathrm{B}$, the seismogenic fault should be locked; however, the linear increase in strain at a rate larger than $3.3 \mathrm{~mm} / \mathrm{yr}$ in the eastward direction demonstrates that elastic strain continues to accumulate. After point $\mathrm{B}$, approximately two and a half years before the Lushan earthquake, the strain seems to reach its peak and remains constant for stations LS05 and LS06 (Fig. 2) or accumulates at a lower rate at stations LS02 and LS07 (Supplementary Fig. S1); consequently, seismic energy is ready to be released on the seismogenic fault.

Seismic nucleation. Section BC in the eastward displacement time series coincides well with the almost aseismic preslip and upward-cascading process in the laboratory that initiates a relatively large dynamic rupture on the seismogenic fault ${ }^{29-32}$. The seismicity recorded by the Sichuan Seismic Network confirms that the seismic activity at the epicenter is weak, but more seismicity occurred in the epicenter and its adjacent areas during the period from 2011 to 2013 before the Lushan earthquake than during the period from 2008 to 2010 (Fig. 4). This implies that the preslip (nucleation) phase is aseismic and weakens the seismogenic fault ${ }^{28-31}$. Thus, the characteristics of the eastward displacement time series in section BC on approximately two and half years before the Lushan earthquake may be taken as a possible precursor for earthquake forecasting.

Seismic gap of the LTB. Among these stations, LS02 is special, as it is located in the seismic gap between the Lushan and Wenchuan ruptures on the $\mathrm{LTB}^{14,15,24}$, and the station is far from the epicenter of the Lushan earthquake. Moreover, stations LS02 and LS05 are both located near the southern segment of the Pengguan fault that did not rupture during the Wenchuan earthquake. However, the accumulated strain at LS05 reached its peak, and an anomaly involving eastward displacement occurred before the Lushan earthquake; this is in contrast to LS02, which still recorded an eastward displacement. To a certain extent, this may explain why the earthquake occurred near station LS05 rather than near station LS02 and why the fault segment between the Lushan and Wenchuan earthquakes did not rupture.

Reductions in eastward velocity. As shown in Fig. 2 and Supplementary Figs. S1, significant reductions in velocity are observed only for the eastward displacements for the near-field stations. This can be explained by the regional tectonic background motion within the LTB and its adjacent areas. Both geodetic observations and tectonic research have verified that the regional principal compressive stresses are oriented nearly E- $\mathrm{W}^{33-35}$. Thus, before the Lushan earthquake, the strain accumulation rate in the E-W direction was greater than that in the N-S direction. Another reason why we focus predominantly on the eastward component is that only three reference stations can be used to control the regional reference frame (Fig. 1). The eastward displacement of the South China Block calculated from these three stations is sufficiently stable to ensure the reliability of the results, whereas the northward displacement exhibits fluctuation (Supplementary Fig. S2).

\section{Data and methods}

GPS data were collected from the temporary continuous GPS network. Nine of the stations have been operating since 2008, whereas station LS09 was installed in 2010 at a site more than $130 \mathrm{~km}$ northwest of the epicenter of the Lushan earthquake. Thus, in our research, we analyzed GPS data from the 9 sites (other than LS09). We obtained the preseismic displacement time series data from the 2005 International Terrestrial Reference System (ITRF2005) that were processed by GAMIT/GLOBK. Then, we transform the observations into the South China Block framework and filter time series with stacking and the least-squares collocation method (see the Supplementary).

The Lushan earthquake occurred on the southern segment of the LTB almost 5 years after the Wenchuan earthquake, and its epicenter is located within the domain of the newly installed continuous GPS network (Fig. 1). Since most of these GPS stations were affected by the Wenchuan earthquake, the postseismic displacement of the earthquake at each GPS station is simulated (see the Supplementary) by using a half-space dislocation model ${ }^{36}$. A Maxwell body and a layered structure model (see the Supplementary Materials) are used in the simulation.

\section{Data availability}

The data that support the findings of this study are available from the Institute of Earthquake Forecasting, China Earthquake Administration, but restrictions apply to the availability of these data, which were used under license for the current study, and so are not publicly available. Data are however available from the first author (Email: qixin0321@163.com) upon reasonable request and with permission of the Institute of Earthquake Forecasting, China Earthquake Administration.

Received: 26 June 2020; Accepted: 13 November 2020

Published online: 30 November 2020 


\section{References}

1. Geller, R. J., Jackson, D. D., Kagan, Y. Y. \& Mulargia, F. Earthquakes cannot be predicted. Science 275, 1616 (1997).

2. Riga, G. \& Balocchi, P. How to identify foreshocks in seismic sequences to predict strong earthquakes. Open J. Earthq. Res. 06, 55-71 (2017).

3. Cicerone, R. D., Ebel, J. E. \& Britton, J. A systematic compilation of earthquake precursors. Tectonophysics 476, 371-396 (2009).

4. Bakun, W. H. \& Lindh, A. G. The Parkfield, California, earthquake prediction experiment. Science 229, 619-624 (1985).

5. Bakun, W. H. et al. Implications for prediction and hazard assessment from the 2004 Parkfield earthquake. Nature 437, 969-974 (2005).

6. Niu, F., Silver, P. G., Daley, T. M., Cheng, X. \& Majer, E. L. Preseismic velocity changes observed from active source monitoring at the Parkfield SAFOD drill site. Nature 454, 204-208 (2008).

7. Kaftan, V. \& Melnikov, A. Local deformation precursors of large earthquakes derived from GNSS observation data. In World Multidisciplinary Earth Sciencess Symposium, 1-13 (2017).

8. Ogata, Y. Pre-seismic anomalies in seismicity and crustal deformation:case studies of the 2007 Noto Hanto earthquake of M6.9 and the 2007 Chuetsu-oki earthquake of M6.8 after the 2004 Chuetsu earthquake of M68. Geophys. J. Int. 186, 331-348 (2011).

9. Sharma, G., Ray, P. K. C., Mohanty, S. \& Kannaujiya, S. Lonospheric tec modeling for earthquakes precursors from GNSS data. Quat. Int. 462(dec.30), 65-74 (2017).

10. Crampin, S., Gao, Y. \& Peacock, S. Stress-forecasting (not predicting) earthquakes: a paradigm shift. Geology 36, 427-430 (2008).

11. Rubinstein, J. L., Ellsworth, W. L., Chen, K. H. \& Uchida, N. Fixed recurrence and slip models better predict earthquake behavior than the time- and slip-predictable models: 1. Repeating earthquakes. J. Geophys. Res. Solid Earth 117, B02306 (2012).

12. Chen, S. F., Wilson, C. J. L., Deng, Q. D., Zhao, X. L. \& Zhi, L. L. Active faulting and block movement associated with large earthquakes in the Min Shan and Longmen Mountains, Northeastern Tibetan Plateau. J. Geophys. Res. Solid Earth 99, 24025-24038 (1994).

13. Densmore, A. L. et al. Active tectonics of the Beichuan and Pengguan faults at the eastern margin of the Tibetan Plateau. Tectonics 26, TC4005 (2007).

14. Xu, X. et al. Coseismic reverse- and oblique-slip surface faulting generated by the $2008 \mathrm{Mw} 7.9$ Wenchuan earthquake. China. Geol. 37, 515-518 (2009)

15. Xu, X. et al. Lushan M S7.0 earthquake: a blind reserve-fault event. Chin. Sci. Bull. 58, 3437-3443 (2013).

16. Wang, Q. et al. Rupture of deep faults in the 2008 Wenchuan earthquake and uplift of the Longmen Shan. Nat. Geosci. 4, 634-640 (2011).

17. Lu, R. et al. Seismotectonics of the 2013 Lushan M w 6.7 earthquake: inversion tectonics in the Eastern margin of the Tibetan Plateau. Geophys. Res. Lett. 44, 8236-8243 (2017).

18. Parsons, T., Ji, C. \& Kirby, E. Stress changes from the 2008 Wenchuan earthquake and increased hazard in the Sichuan basin. Nature 454, 509-510 (2008)

19. Toda, S., Lin, J., Meghraoui, M. \& Stein, R. S. 12 May $2008 \mathrm{M}=7.9$ Wenchuan, China, earthquake calculated to increase failure stress and seismicity rate on three major fault systems. Geophys. Res. Lett. 35, 814-819 (2008).

20. Shen, Z.-K. et al. Slip maxima at fault junctions and rupturing of barriers during the 2008 Wenchuan earthquake. Nat. Geosci. 2, 718-724 (2009).

21. Jiang, Z. et al. GPS constrained coseismic source and slip distribution of the 2013 Mw6.6 Lushan, China, earthquake and its tectonic implications. Geophys. Res. Lett. 41, 407-413 (2014).

22. Wang, Q. et al. Viscoelastic behavior of the crust around the Longmenshan Thrust Belt inferred from post-seismic deformation of the 2013 Lushan earthquake, China. J. Asian Earth Sci. 173, 386-396 (2019).

23. Pei, S., Zhang, H., Su, J. \& Cui, Z. Ductile gap between the Wenchuan and Lushan earthquakes revealed from the two-dimensional Pg seismic tomography. Sci. Rep. 4, 6489 (2014).

24. Gao, Y., Wang, Q., Zhao, B. \& Shi, Y. A rupture blank zone in middle South part of Longmenshan faults: effect after Lushan M s7.0 earthquake of 20 April 2013 in Sichuan China. Sci. China Earth Sci. 57, 2036-2044 (2014).

25. Wan, Y. G., Shen, Z. K., Burgmann, R., Sun, J. \& Wang, M. Fault geometry and slip distribution of the $2008 \mathrm{M}_{\mathrm{w}} 7.9 \mathrm{Wenchuan}$ China earthquake, inferred from GPS and InSAR measurements. Geophys. J. Int. 208, 748-766 (2017).

26. Papadimitriou, E., Wen, X., Karakostas, V. \& Jin, X. Earthquake triggering along the Xianshuihe fault zone of Western Sichuan, China. Pure Appl. Geophys. 161, 1683-1707 (2004).

27. Jiang, G. et al. Joint analysis of the 2014 Kangding, Southwest China, earthquake sequence with seismicity relocation and InSAR inversion. Geophys. Res. Lett. 42, 3273-3281 (2015).

28. Wang, Q. et al. Present-day crustal deformation in China constrained by global positioning system measurements. Science 294, 574-577 (2001).

29. Kaneko, Y., Nielsen, S. B. \& Carpenter, B. M. The onset of laboratory earthquakes explained by nucleating rupture on a rate-andstate fault. J. Geophys. Res. Solid Earth 121, 6071-6091 (2016).

30. Noda, H., Nakatani, M. \& Hori, T. Large nucleation before large earthquakes is sometimes skipped due to cascade-up-Implications from a rate and state simulation of faults with hierarchical asperities. J. Geophys. Res. Solid Earth 118, 2924-2952 (2013).

31. McLaskey, G. C. \& Lockner, D. A. Preslip and cascade processes initiating laboratory stick slip. J. Geophys. Res. Solid Earth 119, 6323-6336 (2014).

32. Kaneko, Y., Carpenter, B. M. \& Nielsen, S. B. Nucleation process of magnitude 2 repeating earthquakes on the San Andreas fault predicted by rate-and-state fault models with SAFOD drill core data. Geophys. Res. Lett. 44, 162-173 (2017).

33. Li, Z. et al. Late Cenozoic east-west crustal shortening in southern Longmen Shan, eastern Tibet: implications for regional stress field changes. Tectonophysics 623, 169-186 (2014).

34. Gan, W. et al. Present-day crustal motion within the Tibetan Plateau inferred from GPS measurements. J. Geophys. Res. 112, 582-596 (2007).

35. Du, F., Wen, X.-Z., Zhang, Z. \& Wang, Q. L. Interseismic deformation across the Longmenshan fault zone before the $2008 \mathrm{M} 80$ Wenchuan earthquake. Chin. J. Geophys. (Acta Geophys. Sin.) 52, 2729-2738 (2009).

36. Wang, R., Lorenzo-Martín, F. \& Roth, F. PSGRN/PSCMP-a new code for calculating co- and post-seismic deformation, geoid and gravity changes based on the viscoelastic-gravitational dislocation theory. Comput. Geosci. 32, 527-541 (2006).

\section{Acknowledgements}

We thank Dr. Wu Yanqiang and Wang Rongjiang for providing the LSCM and PSCMP/PSGRN softwares and China Earthquake Administration for providing GPS data and small earthquakes locations. We gratefully thank the editor and anonymous reviewers for their constructive suggestions that significantly improve the original manuscript. Funding: This work is supported by the Scientific Research Fund of Institute of Crustal Dynamics, CEA (ZDJ2019-29); and the National Key Research and Development Program of China(2018YFC1504104). 


\section{Author contributions}

Q.W. was responsible for GPS data interpretation and paper writing. X.X. help the data interpretation and modify the paper. Z.J. contribute to the data processing and collecting. J.S. help modify the paper.

\section{Competing interests}

The authors declare no competing interests.

\section{Additional information}

Supplementary information is available for this paper at https://doi.org/10.1038/s41598-020-77634-6.

Correspondence and requests for materials should be addressed to X.X.

Reprints and permissions information is available at www.nature.com/reprints.

Publisher's note Springer Nature remains neutral with regard to jurisdictional claims in published maps and institutional affiliations.

(c) (i) Open Access This article is licensed under a Creative Commons Attribution 4.0 International cc) License, which permits use, sharing, adaptation, distribution and reproduction in any medium or format, as long as you give appropriate credit to the original author(s) and the source, provide a link to the Creative Commons licence, and indicate if changes were made. The images or other third party material in this article are included in the article's Creative Commons licence, unless indicated otherwise in a credit line to the material. If material is not included in the article's Creative Commons licence and your intended use is not permitted by statutory regulation or exceeds the permitted use, you will need to obtain permission directly from the copyright holder. To view a copy of this licence, visit http://creativecommons.org/licenses/by/4.0/.

This is a U.S. Government work and not under copyright protection in the US; foreign copyright protection may apply 2020 